lift is greatest in mid-downstroke, so this should be the phase when the thorax is compressed by the flight muscles ${ }^{11}$. However, as usual, things are not so simple because forces at the wing root are dominated by wing inertia, not by lift: the greatest force to pull the wing downwards occurs at the end of the upstroke 9 . It is at this phase that air is expelled from the lungs, and the bat emits its echolocation pulse 'on the back' of breathing out.

This is the mechanism by which echolocation, respiration and flight in microbats are related, and it explains why echolocation in flight is relatively economic. The bat must respire to obtain oxygen for flight, and can use the exhaled air pulses to carry its ultrasonic cries with minimal extra physiological or energetic cost. This also fits with the scarcity of echolocation in non-flying tetrapods: exhaled airflows are not sufficiently concentrated to carry enough sound energy to make echolocation worthwhile. Echolocation is not found in most birds because - in comparison with vision - it is of little use to a daytime flier' there is much still to tell about its absence in birds such as owls and nightjars.

More puzzling is the lack of ultrasonic echolocation in the megabats, where it is confined to a crude form in the cave-dwelling Rousettus. As nocturnal fliers, megabats would undoubtedly benefit from it for orientation, even if it cannot help much in finding fruit or nectar. In this context the absence (or loss?) of echolocation in this group is surprising: microbats have a much older fossil record, and the earliest known Palaeocene microbats were already echolocating aerial insectivores. This apparent discrepancy is however fully consistent with the belief that bats are diphyletic ${ }^{12}$, that megabats evolved from primates sometime after microbats had become established; primates already possessed well-developed vision, and the evolutionary pressures surrounding the development of echolocation in the visually acute proto-megabats may not have been sufficient to favour the extreme specialization it would have involved.

Jeremy M. V. Rayner is in the Department of Zoology, University of Bristol, Woodland Road, Bristol BS8 1UG, UK.

1. Speakman, J. R. \& Racey, P. A. Nature 350, 421-423 (1991)

2. Speakman, J. R., Anderson, M. E. \& Racey, P. A. J. comp. Physiol. A165, 679-685 (1989).

Bramble. D. M. Am. Zool. 29, 171-186 (1989)

4. Carrier, D. R. J.exp. Biol. 143, 435-457 (1989).

5. Alexander, R. MCN. J. Zool., Lond. 218, 69-85 (1989).

6. Duncker, H.-R. in Complex Organismal Functions Integration and Evolution in Vertebrates (eds Wake, D. B. \& Roth, G.) 147-169 (Wiley, New York, 1989).

7. Butler, P. J. \& Woakes, A. J. in Bird Migration (ed. Gwinner, E.) $300-318$ (Springer, Heidelberg, 1990)

E. Jenkins, F. A., Dial, K. P. \& Goslow, G. E. Science 241,
8. 1495-1498 (1988).

9. Rayner, J. M. V. in Recent Advances in the Study of Bats (eds Fenton, M. B., Racey, P. A. \& Rayner, J. M. V.) 23-42 (Cambridge University Press, 1987)

10. Schnitzler, H.-U. Z. vergl. Physiol. 73, 209-221 (1971)

11. Thomas, S. P. in Recent Advances in the Study of Bats (eds Fenton, M. B., Racey, P. A. \& Rayner, J. M. V.) 75-99 (Cambridge University Press, 1987).

12. Pettigrew, J. B. et al. Phil. Trans. R. Soc. Lond. B325. $489-559$ (1989).

\section{Diamond mill}

THE distant dream of controlled nuclear fusion continues to absorb billions of pounds of taxpayers' money. Laser fusion is probably the current front runner. This requires a tiny fuel pellet containing tritium and deuterium to be dropped through an optical focus on which a number of powerful pulsed lasers are aimed. As the pellet reaches the focal point, the lasers all fire at once, hitting the pellet from all directions with hundreds of kilojoules of energy packed into a few nanoseconds. Its surface is vaporized. Such is the inertia of material on this short time scale that the expanding vapour cannot simply boil away. It squeezes and heats the inside of the pellet to nuclear fusion point, releasing a sudden flare of energy. In a working power station, fuel pellets will be dropped into the fusion chamber as fast as the lasers can recycle maybe twenty times a second. Gigawatts of power will result.

Well, that's the dream, the crock of gold at the laser's end. Daedalus now proposes that the vastly expensive fusion laboratories should earn some honest money in the meantime. They study other matters as well, of course; this journal recently carried a letter from one of them concerning the transformation of graphite into diamond (Erskine, D. J. and Nellis, W.J. Nature 349, $317 ; 1991)$. It seems that this is a fast, martensitic process. It takes only ten nanoseconds, just about the length of a fusion-laser pulse, and needs - a mere 300,000 atmospheres - far below what can be achieved by laser-compression. So Daedalus now suggests that the laser-fusion workers abandon their silly little pellets of deuterium-tritium mixture, and start dropping spheres of graphite into their laser-focus.

Crude calculations suggest that existing inertial-confinement laser systems might well be able to transform a 20 -gram graphite pellet into a 50-carat diamond at every pulse. At an output rate of $20 \mathrm{~Hz}$, even allowing for the expense of cutting and polishing the gems, this could bring in well over a million pounds a second. If used to generate fusion electricity, the same equipment would be lucky to bring in a million pounds a week.

Fusion lasers on the drawing board are ten times more powerful still, making posible the mass-production of diamonds up to 500 carats or so. World prices will undoubtedly tumble, and de Beers will be apoplectic, but even so the operation should turn in a tidy profit. Mass-produced bulk diamonds will be wonderfully useful for spectroscopic windows and prisms, heatsinks, cutting-tools, chemical flasks and crucibles, and cheap jewellery of all kinds. Elegant socialites will attend glittering receptions in their diamond tiaras, while leaving the real paste ones carefully locked in the safe.

David Jones 